\title{
A systematic review and meta-analysis of bidirectional effect of arsenic on ERK signaling pathway
}

\author{
DONGJIE LI ${ }^{1 *}$, YUTAO WEI $^{2 *}$, SHANGZHI XU $^{1}$, QIANG NIU ${ }^{1}$, MEI ZHANG ${ }^{1}$, SHUGANG LI $^{1}$ and MINGXIA JING ${ }^{1}$ \\ ${ }^{1}$ Department of Public Health, School of Medicine, Shihezi University, Shihezi, Xinjiang 832002; ${ }^{2}$ Department of \\ Cardiothoracic Surgery, First Affiliated Hospital, School of Medicine, Shihezi University, Shihezi, Xinjiang 832000, P.R. China
}

Received May 9, 2017; Accepted November 21, 2017

DOI: $10.3892 / \mathrm{mmr} .2018 .8383$

\begin{abstract}
Arsenic is a toxic metal, which ultimately leads to cell apoptosis. ERK is considered a key transcriptional regulator of arsenic-induced apoptosis. Due to a few controversial issues about arsenic-mediated extracellular signal-regulated MAP kinases (ERK) signaling, a meta-analysis was performed. Subgroup analyses demonstrated that high doses $(\geq 2 \mu \mathrm{mol} / \mathrm{l})$ of arsenic increased the expression of Ras, ERK, ERK1, ERK2, phosphorylated (p)-ERK, p-ERK1, and p-ERK2, while low doses $(<2 \mu \mathrm{mol} / \mathrm{l})$ decreased the expression of Ras, ERK1, p-ERK, and p-ERK2 when compared to control groups. Long term exposure $(>24 \mathrm{~h})$ to arsenic led to inhibition of expression of ERK1, p-ERK1, and p-ERK2, whereas short-term exposure $(\leq 24 \mathrm{~h})$ triggered the expression of ERK1,ERK2,p-ERK, p-ERK1, and p-ERK2.Furthermore, normal cells exposed to arsenic exhibited higher production levels of Ras and p-ERK. Conversely, exposure of cancer cells to arsenic showed a lower level of production of Ras and p-ERK as well as higher level of p-ERK1 and p-ERK2 as compared to control group. Short-term exposure of normal cells to high doses of arsenic may promote ERK signaling pathway. In contrast, long-term exposure of cancer cells to low doses of arsenic may inhibit ERK signaling pathway. This study may be helpful in providing a theoretical basis
\end{abstract}

Correspondence to: Professor Shugang Li or Professor Mingxia Jing, Department of Public Health, School of Medicine, Shihezi University, North 4th Road, Shihezi, Xinjiang 832002, P.R. China

E-mail: lishugang@ymail.com

E-mail: jingmingxia126@126.com

"Contributed equally

Abbreviations: MAPK, mitogen-activated protein kinases; ERK, extracellular signal-regulated MAP kinases; MEK, mitogen-induced extracellular kinase; p-ERK, phosphorylated extracellular signal-regulated kinase; caspase-3, cysteinyl aspartate-specific protease-3; Bcl-2, B-cell lymphoma/leukemia-2 protein; Bax, Bcl-associated X protein

Key words: arsenic, extracellular signal-regulated MAP kinases, bidirectional effect, apoptosis, meta-analysis for the diverging result of arsenic adverse effects on one hand and therapeutic mechanisms on the other concerning arsenic-induced apoptosis.

\section{Introduction}

Arsenic (As) is a naturally occurring toxic metal which was classified as potentially poisonous substance (1). Excessive exposure to arsenic damages multiple organs (2). Presently, a mounting number of studies preferably examined the molecular mechanisms of apoptosis induced by arsenic $(3,4)$. It was believed that the mitogen-activated protein kinases (MAPK) signaling pathway was implicated in cell injury, proliferation, and apoptosis (5). The extracellular signal-regulated MAP kinases (ERK), an important member of the MAPK families, became phosphorylated and activated in response to diverse environmental stimuli (6).

It had been postulated that ERK was consequently a participant in arsenic-induced apoptosis $(7,8)$. In all these studies, however, not all scholars were in agreement on the issue of arsenic mediating ERK signaling. EscuderoLourdes et al (9) found that exposure of urothelial cells to $0.05 \mu \mathrm{mol} / 1$ of arsenic for 12 months significantly increased protein expression of p-ERK1 and p-ERK2, which indicated that the ERK signaling pathway was activated by arsenic. Conversely, Wang et al (10) drew a different conclusion stating that arsenic restrained the ERK signaling pathway due to the fact that inhibition and lowering of p-ERK1 and p-ERK2 levels were observed in human leukemia cell lines after being exposed to $2.5 \mu \mathrm{mol} / 1$ of arsenic for $24 \mathrm{~h}$. Evidently, the effects of arsenic on ERK signaling pathway remained a debatable issue.

To probe the role of ERK signaling pathway in arsenic-induced apoptosis, a meta-analysis of experimental studies published in domestic and foreign literature was performed in our paper. The present study may be helpful in providing a theoretical basis for the diverging result of arsenic adverse effects on one hand and therapeutic mechanisms on the other concerning arsenic-induced apoptosis.

\section{Materials and methods}

Inclusion criteria. Inclusion Criteria and literature search terms were identified according to the PICO principle. 
Study design. Experimental studies published in Chinese and English.

Participants $(P)$. All cell lines and animals, disregarding age, gender and weight.

Intervention (I). All experimental groups treated with any kind of arsenic or its compounds. Arsenic model groups might show the change in indicators associated with ERK signaling pathway and apoptosis. If variable dosages of arsenic or exposure times were used in a study, the highest or longest one was chosen for this analysis.

Comparison $(C)$. The control group without any intervention (blank control group).

Outcome $(\mathrm{O})$.Following indicators in mediating of ERK signaling were used, Ras (or p21) protein, Raf protein, Mitogen-induced extracellular kinase (MEK), Total extracellular signal-regulated MAP kinases (ERK), Extracellular signal-regulated kinase 1 (ERK1), Extracellular signal-regulated kinase 2 (ERK2), Total phosphorylated extracellular signal-regulated kinase (p-ERK), Phosphorylated extracellular signal-regulated kinase 1 (p-ERK1), Phosphorylated extracellular signal-regulated kinase 2(p-ERK2), Cysteinyl aspartate-specific protease-3 (caspase-3), Apoptotic cells (\%), Pro-apoptotic protein-Bcl-associated X protein (Bax), Anti-apoptotic protein-B-cell lymphoma/leukemia-2 protein (Bcl-2).

Exclusion criteria. We excluded the studies upon following criteria: i) the papers focused only on ERK but not arsenic; ii) the papers focused on arsenic without investigating ERK; iii) no outcome indicators (as stated in '2.1.5 Outcome'); iv) duplicate publications; v) review articles; vi) inadequate information; and vii) no available data.

Search strategy. A systematic search was conducted using Cochrane Library, PubMed, Excerpta Medica database (EMBASE), Springer, Web of Science, Chinese Biomedical Literature Database (CBM), China National Knowledge Infrastructure (CNKI) and Wan Fang Data databases (last search conducted on January 24th, 2017). The key search string was 'arsenic AND (Ras OR Raf OR MEK OR ERK)'.

Quality assessment. The Cochrane collaboration's tool for bias risk assessment was used to evaluate the quality of 42 articles identified in the present study. The evaluation system consisted of seven aspects, viz. i) Random sequence generation (selection bias); ii) allocation concealment (selection bias); iii) blinding of participants and personnel (performance bias); iv) blinding of outcome assessment (detection bias); v) incomplete outcome data (attrition bias); vi) Selective reporting (reporting bias); and vii) other bias. The rating criteria were as follows, low risk of bias, unclear risk of bias and high risk of bias.

Data collection. Two reviewers (Dongjie Li and Yutao Wei) independently extracted data which was then cross-checked before putting the results into a collective spreadsheet. If the results seem to be inconsistent, Dr. Shugang Li and

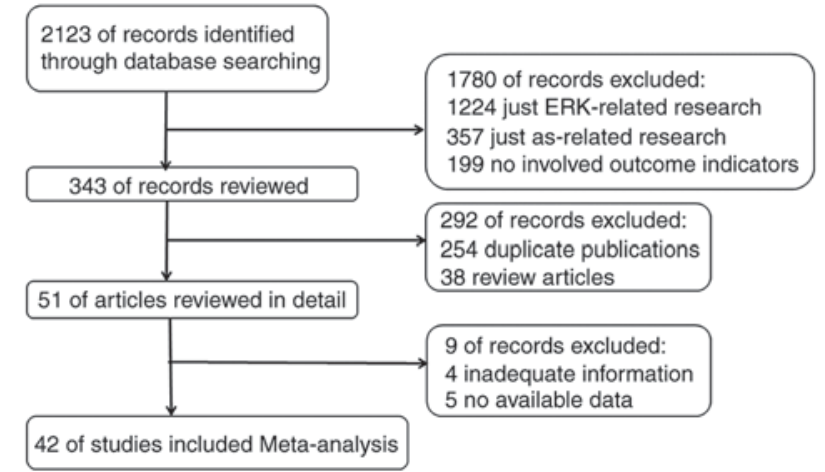

Figure 1. Flow chart of identifying and including studies. ERK, extracellular signal-regulated MAP kinases.

Mingxia Jing were asked to verify before final confirmation. The following information was documented meticulously out of completed manuscripts from each qualified study: i) information about the paper including title, first author, publication date and the name of the journal where published; ii) characteristics of the research object including the type and source of cell lines and breed of animals; iii) type, dosage and exposure time of arsenic; iv) outcome indicators; and v) baseline data for experimental and control groups, viz. number of groups (n), mean and standard deviation (SD).

Data analysis. Forty-two articles were analyzed using Review Manager Version 5.2 (The Nordic Cochrane Centre, The Cochrane Collaboration 2012, Portland, OR, USA) and Stata 12.0 (StataCorp LP, College Station, TX, USA). Standardized mean difference (SMD) was chosen for consolidating statistical data. Heterogeneity was detected by calculating the $\mathrm{I}^{2}$ index. $\mathrm{I}^{2} \leq 50 \%$ and $>50 \%$ represented low and high levels of heterogeneity, respectively. Random effects model was chosen when $\mathrm{P}<0.05$ and $\mathrm{I}^{2}>50 \%$, and fixed effects model was used when $\mathrm{P}>0.05$ and $\mathrm{I}^{2} \leq 50 \%$. Subgroup analyses and meta-regression analyses (including univariate and multivariate meta-regression analyses) were conducted to examine sources of heterogeneity among 42 studies. Subgroup analyses were performed on the basis of the source (normal and cancer cells), exposure time ( $>24 \mathrm{~h}$ and $\leq 24 \mathrm{~h}$ ) and dosage of arsenic ( $\geq 2$ and $<2 \mu \mathrm{mol} / \mathrm{l}$ ). The combined effect was estimated as SMD with $95 \%$ confidence interval (95\% CI) between arsenic model and control group. All reported P-values were two-sided and $\mathrm{P}<0.05$ was considered to indicate a statistically significant difference. Small-study effects were assessed by using funnel plots. Egger's tests and sensitivity analyses were conducted using Stata 12.0.

\section{Results}

Search results. A total of 2,123 articles were initially identified by search criteria. Utilizing our inclusion and exclusion criteria, 42 of those articles were qualified for meta-analysis (Fig. 1).

Basic characteristics of included studies. Characteristics of the studies included in this meta-analysis were listed in Table I. In the present study, the effects of arsenic on ERK signaling pathway was assessed. Arsenic model groups encompasses 
Table I. Characteristics of the studies included in the meta-analysis.

\begin{tabular}{|c|c|c|c|c|c|c|c|c|}
\hline Author (Refs.) & Year & Language & $\mathrm{n}$ & $\begin{array}{c}\text { Type of } \\
\text { arsenical } \\
\text { compounds }\end{array}$ & $\begin{array}{c}\text { Dosage of } \\
\text { arsenic, } \\
\mu \mathrm{mol} / 1\end{array}$ & $\begin{array}{c}\text { Time of } \\
\text { exposure, } \\
h\end{array}$ & $\begin{array}{l}\text { Type of } \\
\text { cells }\end{array}$ & $\begin{array}{l}\text { Outcome } \\
\text { indicators }\end{array}$ \\
\hline Yen et al (2) & 2011 & English & 12 & $\mathrm{As}_{2} \mathrm{O}_{3}$ & $<2$ & $>24$ & Normal cells & $5,6,8,9,11,12$ \\
\hline Eguchi et al (3) & 2011 & English & 3 & $\mathrm{As}_{2} \mathrm{O}_{3}$ & $\geq 2$ & $\leq 24$ & Cancer cells & $5,6,8,9,11$ \\
\hline Ray et al (4) & 2013 & English & 3 & $\mathrm{As}_{2} \mathrm{O}_{3}$ & $\geq 2$ & $\leq 24$ & Normal cells & $4,7,11$ \\
\hline Lau et al (5) & 2004 & English & 3 & $\mathrm{NaAsO}_{2}$ & $\geq 2$ & $\leq 24$ & Normal cells & $5,6,8,9$ \\
\hline Li et al (6) & 2006 & English & 3 & $\mathrm{NaAsO}_{2}$ & $\geq 2$ & $\leq 24$ & Cancer cells & $6,8,9$ \\
\hline $\begin{array}{l}\text { Lozano-Santos } \\
\text { et al }(7)\end{array}$ & 2015 & English & 3 & $\mathrm{As}_{2} \mathrm{O}_{3}$ & $<2$ & $>24$ & Cancer cells & $7,12,13$ \\
\hline Ge et al (8) & 2005 & Chinese & 3 & $\mathrm{AA}$ & $\geq 2$ & $>24$ & Cancer cells & 10 \\
\hline $\begin{array}{l}\text { Escudero-Lourdes } \\
\text { et al (9) }\end{array}$ & 2010 & English & 3 & MMA & $<2$ & $>24$ & Normal cells & $4,5,6,8,9$ \\
\hline Wang et al (10) & 2012 & Chinese & 3 & $\mathrm{As}_{2} \mathrm{O}_{3}$ & $\geq 2$ & $\leq 24$ & Cancer cells & $8,9,11$ \\
\hline Daum et al (11) & 2001 & English & 3 & $\mathrm{NaAsO}_{2}$ & $\geq 2$ & $\leq 24$ & Normal cells & 8,9 \\
\hline $\begin{array}{l}\text { Benbrahim-Tallaa } \\
\text { et al (12) }\end{array}$ & 2005 & English & 3 & $\mathrm{NaAsO}_{2}$ & $\geq 2$ & $>24$ & Normal cells & 1 \\
\hline Chowdhury et al (13) & 2010 & English & 3 & $\mathrm{NaAsO}_{2}$ & $\geq 2$ & $\leq 24$ & Normal cells & $5,6,8,9$ \\
\hline Li et al (14) & 2010 & Chinese & 3 & $\mathrm{NaAsO}_{2}$ & $\geq 2$ & $\leq 24$ & Normal cells & 7 \\
\hline Suzuki et al (15) & 2011 & English & 3 & $\mathrm{As}_{2} \mathrm{O}_{3}$ & $\geq 2$ & $\leq 24$ & Cancer cells & $5,6,8,9$ \\
\hline Guilbert et al (16) & 2013 & English & 3 & As2O3 & $\geq 2$ & $\leq 24$ & Cancer cells & $4,8,9$ \\
\hline Huff et al (17) & 2016 & English & 3 & $\mathrm{NaAsO}_{2}$ & $<2$ & $\leq 24$ & Cancer cells & $5,6,8,9$ \\
\hline Wang et al (18) & 2012 & English & 3 & $\mathrm{As}_{2} \mathrm{O}_{3}$ & $\geq 2$ & $\leq 24$ & Normal cells & $5,6,8,9(18)$ \\
\hline $\begin{array}{l}\text { Aodengqimuge } \\
\text { et al (19) }\end{array}$ & 2014 & English & 3 & $\mathrm{NaAsO}_{2}$ & $\geq 2$ & $\leq 24$ & Normal cells & $4,7,10$ \\
\hline Gong et al (20) & 2016 & English & 3 & $\mathrm{NaAsO}_{2}$ & $\geq 2$ & $\leq 24$ & Normal cells & $5,6,8,9,10,12$ \\
\hline Person et al (21) & 2015 & English & 3 & $\mathrm{NaAsO}_{2}$ & $\geq 2$ & $>24$ & Normal cells & $1,4,7$ \\
\hline Huang et al (22) & 1999 & English & 3 & $\mathrm{NaAsO}_{2}$ & $\geq 2$ & $\leq 24$ & Cancer cells & $5,6,8,9$ \\
\hline $\begin{array}{l}\text { Martinez-Finley } \\
\text { et al (23) }\end{array}$ & 2011 & English & 4 & $\mathrm{NaAsO}_{2}$ & $<2$ & $>24$ & Normal cells & $1,2,5,6,8,9$ \\
\hline Estañ et al (24) & 2012 & English & 3 & $\mathrm{As}_{2} \mathrm{O}_{3}$ & $\geq 2$ & $\leq 24$ & Cancer cells & $5,6,8,9,10,11,12$ \\
\hline Zheng et al (25) & 2006 & Chinese & 3 & $\mathrm{As}_{2} \mathrm{O}_{3}$ & $\geq 2$ & $\leq 24$ & Cancer cells & $4,10,11$ \\
\hline Zhang et al (26) & 2015 & Chinese & 3 & $\mathrm{NaAsO}_{2}$ & $\geq 2$ & $>24$ & Normal cells & $1,2,3,5,6,7$ \\
\hline Luo et al (27) & 2012 & Chinese & 3 & $\mathrm{NaAsO}_{2}$ & $\geq 2$ & $\leq 24$ & Normal cells & $5,6,8,9,10,11,12,13$ \\
\hline Banerjee et al (28) & 2011 & English & 3 & As2O3 & $<2$ & $\leq 24$ & Normal cells & $4,7,11$ \\
\hline Wu et al (29) & 2008 & Chinese & 3 & $\mathrm{As}_{2} \mathrm{O}_{3}$ & $\geq 2$ & $>24$ & Cancer cells & $8,9,10,13$ \\
\hline Li et al (30) & 2016 & Chinese & 8 & $\mathrm{As}_{2} \mathrm{O}_{3}$ & $<2$ & $\leq 24$ & Cancer cells & $1,2,3,4,11,12,13$ \\
\hline Ye (31) & 2006 & Chinese & 3 & $\mathrm{As}_{2} \mathrm{O}_{3}$ & $<2$ & $\leq 24$ & Cancer cells & $5,6,10$ \\
\hline Iwama et al (32) & 2001 & English & 3 & $\mathrm{As}_{2} \mathrm{O}_{3}$ & $\geq 2$ & $\leq 24$ & Cancer cells & $3,5,6,8,9,10,11,13$ \\
\hline Calviño et al (33) & 2011 & English & 3 & $\mathrm{As}_{2} \mathrm{O}_{3}$ & $\geq 2$ & $\leq 24$ & Cancer cells & $4,7,10,11,12$ \\
\hline Liu et al (34) & 2006 & English & 3 & $\mathrm{As}_{2} \mathrm{O}_{3}$ & $\geq 2$ & $\leq 24$ & Cancer cells & $1,6,8,9$ \\
\hline Huang et al (35) & 2006 & English & 3 & $\mathrm{As}_{2} \mathrm{O}_{3}$ & $\geq 2$ & $\leq 24$ & Cancer cells & $1,4,5,6,7$ \\
\hline Liao et al (36) & 2015 & English & 3 & $\mathrm{NaAsO}_{2}$ & $\geq 2$ & $\leq 24$ & Normal cells & $5,6,7$ \\
\hline Wang (37) & 2012 & Chinese & 3 & $\mathrm{NaAsO}_{2}$ & $\geq 2$ & $\leq 24$ & Normal cells & 8,9 \\
\hline Ngalame et al (38) & 2014 & English & 3 & $\mathrm{NaAsO}_{2}$ & $\geq 2$ & $>24$ & Normal cells & 1,7 \\
\hline Ju (39) & 2007 & Chinese & 3 & $\mathrm{As}_{2} \mathrm{O}_{3}$ & $\geq 2$ & $\leq 24$ & Cancer cells & $8,9,10,11$ \\
\hline Petit et al (40) & 2013 & English & 3 & $\mathrm{As}_{2} \mathrm{O}_{3}$ & $\geq 2$ & $\leq 24$ & Cancer cells & $5,6,8,9$ \\
\hline
\end{tabular}


Table I. Continued.

\begin{tabular}{|c|c|c|c|c|c|c|c|c|}
\hline Author/(Refs.) & Year & Language & $\mathrm{n}$ & $\begin{array}{c}\text { Type of } \\
\text { arsenical } \\
\text { compounds }\end{array}$ & $\begin{array}{c}\text { Dosage of } \\
\text { arsenic, } \\
\mu \mathrm{mol} / \mathrm{l}\end{array}$ & $\begin{array}{c}\text { Time of } \\
\text { exposure, } \\
h\end{array}$ & $\begin{array}{c}\text { Type of } \\
\text { cells }\end{array}$ & $\begin{array}{l}\text { Outcome } \\
\text { indicators }\end{array}$ \\
\hline Lu et al (41) & 2014 & English & 3 & $\mathrm{As}_{2} \mathrm{O}_{3}$ & $\geq 2$ & $\leq 24$ & Cancer cells & $5,6,8,9,11,12,13$ \\
\hline Liu et al (42) & 2013 & Chinese & 3 & $\mathrm{As}_{2} \mathrm{O}_{3}$ & $<2$ & $>24$ & Cancer cells & 1,7 \\
\hline Zhao et al (43) & 2015 & English & 3 & $\mathrm{As}_{2} \mathrm{O}_{3}$ & $<2$ & $>24$ & Cancer cells & 1 \\
\hline
\end{tabular}

n, number of experimental group; N, normal cells; C, cancer cells; ERK, extracellular signal-regulated MAP kinases; MEK, mitogen-induced extracellular kinase; p-ERK, phosphorylated extracellular signal-regulated kinase; Raf, serine/threonine-specific protein kinases; Bcl-2, B-cell lymphoma/leukemia-2 protein; Bax, Bcl-associated X protein; caspase-3, cysteinyl aspartate-specific protease-3; RTKs, receptor tyrosine kinases. 1, Ras; 2, Raf; 3, MEK; 4, ERK; 5, ERK1; 6, ERK2; 7, p-ERK; 8, p-ERK1; 9, p-ERK2; 10, Apoptotic cells; 11, caspase-3; 12, Bax; 13, Bcl-2.

those cell lines which were treated with various forms of arsenic including sodium arsenite $\left(\mathrm{NaAsO}_{2}\right)$, arsenic trioxide $\left(\mathrm{As}_{2} \mathrm{O}_{3}\right)$, monomethyl arsenous acid (MMA) and arsenious acid (AA). The control models were blank controls without any exposure to arsenic. In subgroup analyses, arsenic exposure time varied among the studies and hence was stratified into $\leq 24 \mathrm{~h}(\mathrm{n}=30)$ and $>24 \mathrm{~h}(\mathrm{n}=12)$. The dosage of arsenic was also variable and thus was differentiated into $\geq 2 \mu \mathrm{mol} / 1 \quad(\mathrm{n}=32)$ and $<2 \mu \mathrm{mol} / 1$ $(n=10)$ groups. Likewise, different cell lines were separated into normal cells $(n=19)$ and cancer cells $(n=23)$. In this review, cancer cells included the following ones, U937 cells (human leukemia cell line), A431 cells (human epidermoid carcinoma cells), CL3 cell line (non-small-cell lung carcinoma cell line), Flt3-ITD cells (acute myeloid leukemia cells), JB6 Cl 41 mass cells, NCI-H2052 cells (human mesothelioma cells), HL-60 cells (human leukemia cell line), SGC7901/ADM (human gastric cancer cell line), MDA-MB-468 (breast cancer cells), SH-SY5Y (human neuroblastoma cells), Neuro-2a cells (murine neuroblastoma cell line), CLL cells (chronic lymphocytic leukemia cell line, but not the WSU-CLL cell line), SGC7901/S (human gastric cancer cell line), NCI-H1793 (non-small-cell lung carcinoma cell line), U-251 MG cells (human glioma cells), NCI-H157 (non-small-cell lung carcinoma cell line), BEL-7402 cells (human hepatocarcinoma cells), FRO (anaplastic thyroid cancer cell line) and Hela cells (cervical cancer cells). NCI-H157 was a misidentified cell line according to http://icl ac.org/wp-content/uploads/Cross-Contaminations-v8_0.pdf.Taking all these factors into consideration, we have arrived at the conclusion that time $(\mathrm{P}=0.012)$ and dosage $(\mathrm{P}=0.037)$ were statistically significant in the univariate meta-regression analysis. Outcome variables were assessed for any association with apoptosis (including apoptotic cells, caspase-3, Bax, and Bcl-2) and ERK signaling pathway (i.e., Ras, Raf, MEK, ERK, ERK1, ERK2, p-ERK, p-ERK1, and p-ERK2).

Quality assessment of included studies. The quality of the 42 articles identified in the study was evaluated (Table II) and the proportion of low risk was accounted for more than $75 \%$ (Fig. 2).

Meta-analysis of arsenic-related apoptosis. A pooled analysis showed that apoptotic cell levels were 3.84-fold higher in arsenic exposed group compared to those of control $(95 \%$ CI $(1.44,6.24))$. Levels of caspase-3 were 11.67 times higher in the exposed group than in control group (95\% CI (7.06, 16.28)). Bax levels were 5.27-fold higher in the exposed group compared to control group (95\% CI $(2.18,8.36))$. Levels of Bcl-2 were 2.08 times lower in the exposed group than in control group (95\% CI (-2.96, -1.21)) (Fig. 3).

Meta-analysis regarding arsenic and level of ERK. Levels of p-ERK1 were 3.59 times higher in exposed group as compared to control group $(95 \% \mathrm{CI}(0.45,6.74))$. The levels of p-ERK2 were comparatively 4.39 times higher in exposed than in control group (95\% CI $(0.12,8.67))$. Raf levels were 1.78 -fold lower in exposed than in control group (95\% CI (-2.72, -0.85)). Similarly, MEK levels were 1.61 times lower in exposed group as compared to control group (95\% CI $(-2.59,-0.63))$. There was no statistical difference in Ras, ERK, ERK1, ERK2, and p-ERK levels ( $\mathrm{P}>0.05)$ (Fig. 4).

\section{Subgroup analyses of arsenic exposure effects}

Subgroup analyses based on sources of arsenic. The analysis had demonstrated that arsenic promoted the expressions of Ras and p-ERK $(\mathrm{P}<0.05)$ in normal cells. Though, in cancer cells, arsenic decreased the expressions of Ras and p-ERK as well as caused an increase in p-ERK1 and p-ERK2 levels $(\mathrm{P}<0.05)$ (Fig. 5).

Subgroup analyses based on exposure time of arsenic. Our results showed that arsenic exposure time of $>24 \mathrm{~h}$ had suppressed the levels of ERK1, p-ERK1, and p-ERK2 $(\mathrm{P}<0.05)$, conversely arsenic exposure time of $\leq 24 \mathrm{~h}$ promoted the levels of ERK1, ERK2, p-ERK, p-ERK1, and p-ERK2 $(\mathrm{P}<0.05)$ (Figs. 6, 7).

Subgroup analyses based on arsenic dose. Subgroup analyses exhibited increased expressions of Ras (SMD=7.29, 95\% CI $(0.90,13.68))$, ERK (SMD=4.62, 95\% CI $(0.17,9.07))$, ERK1 (SMD=5.28, 95\% CI $(1.02,9.54))$, ERK2 (SMD=8.17, $95 \%$ CI $(2.73,13.62)), \mathrm{p}-\mathrm{ERK}(\mathrm{SMD}=6.15,95 \% \mathrm{CI}(0.20$, 12.11)), p-ERK1 (SMD=4.48, 95\% CI $(1.67,7.30))$, p-ERK2 $(\mathrm{SMD}=7.28,95 \%$ CI $(2.87,11.70))$ with high doses of arsenic 
Table II. Quality assessment of included studies.

\begin{tabular}{|c|c|c|c|c|c|c|c|c|}
\hline Author/(Refs.) & Year & 1 & 2 & 3 & 4 & 5 & 6 & 7 \\
\hline Huang et al (22) & 1999 & $\mathrm{~L}$ & $\mathrm{~L}$ & $\mathrm{~L}$ & $\mathrm{~L}$ & $\mathrm{~L}$ & $\mathrm{~L}$ & $\mathrm{~L}$ \\
\hline Iwama et al (32) & 2001 & $\mathrm{~L}$ & $\mathrm{~L}$ & $\mathrm{~L}$ & $\mathrm{~L}$ & $\mathrm{~L}$ & $\mathrm{~L}$ & $\mathrm{~L}$ \\
\hline Daum et al (11) & 2001 & $\mathrm{~L}$ & $\mathrm{U}$ & $\mathrm{L}$ & $\mathrm{L}$ & $\mathrm{L}$ & $\mathrm{L}$ & $\mathrm{L}$ \\
\hline Benbrahim-Tallaa et al (12) & 2005 & $\mathrm{~L}$ & $\mathrm{~L}$ & $\mathrm{~L}$ & $\mathrm{~L}$ & $\mathrm{~L}$ & $\mathrm{~L}$ & $\mathrm{~L}$ \\
\hline Liu et al (34) & 2006 & $\mathrm{~L}$ & $\mathrm{~L}$ & $\mathrm{~L}$ & $\mathrm{~L}$ & $\mathrm{~L}$ & $\mathrm{~L}$ & $\mathrm{~L}$ \\
\hline Huang et al (35) & 2006 & $\mathrm{~L}$ & $\mathrm{~L}$ & $\mathrm{~L}$ & $\mathrm{~L}$ & $\mathrm{~L}$ & $\mathrm{~L}$ & $\mathrm{~L}$ \\
\hline Li et al (6) & 2006 & $\mathrm{~L}$ & $\mathrm{~L}$ & $\mathrm{~L}$ & $\mathrm{~L}$ & $\mathrm{~L}$ & $\mathrm{~L}$ & $\mathrm{~L}$ \\
\hline Chowdhury et al (13) & 2010 & $\mathrm{~L}$ & $\mathrm{~L}$ & $\mathrm{H}$ & $\mathrm{L}$ & $\mathrm{L}$ & $\mathrm{U}$ & $\mathrm{L}$ \\
\hline Li et al (14) & 2010 & $\mathrm{~L}$ & $\mathrm{~L}$ & $\mathrm{~L}$ & $\mathrm{~L}$ & $\mathrm{~L}$ & $\mathrm{~L}$ & $\mathrm{~L}$ \\
\hline Calviño et al (33) & 2011 & $\mathrm{~L}$ & $\mathrm{~L}$ & $\mathrm{~L}$ & $\mathrm{~L}$ & $\mathrm{~L}$ & $\mathrm{~L}$ & $\mathrm{~L}$ \\
\hline Suzuki et al (15) & 2011 & $\mathrm{~L}$ & $\mathrm{~L}$ & $\mathrm{~L}$ & $\mathrm{~L}$ & $\mathrm{~L}$ & $\mathrm{~L}$ & $\mathrm{~L}$ \\
\hline Banerjee et al (28) & 2011 & $\mathrm{~L}$ & $\mathrm{~L}$ & $\mathrm{~L}$ & $\mathrm{~L}$ & $\mathrm{~L}$ & $\mathrm{~L}$ & $\mathrm{~L}$ \\
\hline Eguchi et al (3) & 2011 & $\mathrm{~L}$ & $\mathrm{~L}$ & $\mathrm{~L}$ & $\mathrm{~L}$ & $\mathrm{~L}$ & $\mathrm{~L}$ & $\mathrm{~L}$ \\
\hline Martinez-Finley et al (23) & 2011 & $\mathrm{~L}$ & $\mathrm{~L}$ & $\mathrm{~L}$ & $\mathrm{~L}$ & $\mathrm{~L}$ & $\mathrm{~L}$ & $\mathrm{~L}$ \\
\hline Estañ et al (24) & 2012 & $\mathrm{~L}$ & $\mathrm{~L}$ & $\mathrm{~L}$ & $\mathrm{~L}$ & $\mathrm{~L}$ & $\mathrm{~L}$ & $\mathrm{~L}$ \\
\hline Wang et al (10) & 2012 & $\mathrm{~L}$ & $\mathrm{U}$ & $\mathrm{L}$ & $\mathrm{L}$ & $\mathrm{L}$ & $\mathrm{L}$ & $\mathrm{L}$ \\
\hline Liu et al (42) & 2013 & $\mathrm{~L}$ & $\mathrm{~L}$ & $\mathrm{~L}$ & $\mathrm{~L}$ & $\mathrm{~L}$ & $\mathrm{~L}$ & $\mathrm{~L}$ \\
\hline Guilbert et al (16) & 2013 & $\mathrm{~L}$ & $\mathrm{~L}$ & $\mathrm{~L}$ & $\mathrm{~L}$ & $\mathrm{~L}$ & $\mathrm{~L}$ & $\mathrm{~L}$ \\
\hline Ray et al (4) & 2013 & $\mathrm{~L}$ & $\mathrm{~L}$ & $\mathrm{~L}$ & $\mathrm{~L}$ & $\mathrm{~L}$ & $\mathrm{~L}$ & $\mathrm{~L}$ \\
\hline Ngalame et al (38) & 2014 & $\mathrm{~L}$ & $\mathrm{~L}$ & $\mathrm{~L}$ & $\mathrm{~L}$ & $\mathrm{~L}$ & $\mathrm{~L}$ & $\mathrm{~L}$ \\
\hline Lu et al (41) & 2014 & $\mathrm{~L}$ & $\mathrm{~L}$ & $\mathrm{~L}$ & $\mathrm{~L}$ & $\mathrm{~L}$ & $\mathrm{~L}$ & $\mathrm{~L}$ \\
\hline Lozano-Santos et al (7) & 2015 & $\mathrm{~L}$ & $\mathrm{~L}$ & $\mathrm{H}$ & $\mathrm{L}$ & $\mathrm{L}$ & $\mathrm{L}$ & $\mathrm{L}$ \\
\hline Zhao et al (43) & 2015 & $\mathrm{~L}$ & $\mathrm{~L}$ & $\mathrm{~L}$ & $\mathrm{~L}$ & $\mathrm{~L}$ & $\mathrm{~L}$ & $\mathrm{~L}$ \\
\hline Huff et al (17) & 2016 & $\mathrm{~L}$ & $\mathrm{~L}$ & $\mathrm{~L}$ & $\mathrm{~L}$ & $\mathrm{~L}$ & $\mathrm{~L}$ & $\mathrm{~L}$ \\
\hline Zheng et al (25) & 2006 & $\mathrm{~L}$ & $\mathrm{U}$ & $\mathrm{L}$ & $\mathrm{L}$ & $\mathrm{L}$ & $\mathrm{L}$ & $\mathrm{L}$ \\
\hline Liao et al (36) & 2015 & $\mathrm{~L}$ & $\mathrm{~L}$ & $\mathrm{~L}$ & $\mathrm{~L}$ & $\mathrm{~L}$ & $\mathrm{~L}$ & $\mathrm{~L}$ \\
\hline Wu et al (29) & 2008 & $\mathrm{~L}$ & $\mathrm{~L}$ & $\mathrm{~L}$ & $\mathrm{~L}$ & $\mathrm{~L}$ & $\mathrm{~L}$ & $\mathrm{~L}$ \\
\hline Zhang (26) & 2015 & $\mathrm{~L}$ & $\mathrm{~L}$ & $\mathrm{~L}$ & $\mathrm{~L}$ & $\mathrm{~L}$ & $\mathrm{~L}$ & $\mathrm{~L}$ \\
\hline Escudero-Lourdes et al (9) & 2010 & $\mathrm{~L}$ & $\mathrm{~L}$ & $\mathrm{~L}$ & $\mathrm{~L}$ & $\mathrm{~L}$ & $\mathrm{~L}$ & $\mathrm{~L}$ \\
\hline Yen et al (2) & 2011 & $\mathrm{~L}$ & $\mathrm{~L}$ & $\mathrm{~L}$ & $\mathrm{~L}$ & $\mathrm{~L}$ & $\mathrm{~L}$ & $\mathrm{~L}$ \\
\hline Wang et al (18) & 2012 & $\mathrm{~L}$ & $\mathrm{~L}$ & $\mathrm{~L}$ & $\mathrm{~L}$ & $\mathrm{~L}$ & $\mathrm{~L}$ & $\mathrm{~L}$ \\
\hline Aodengqimuge et al (19) & 2014 & $\mathrm{~L}$ & $\mathrm{~L}$ & $\mathrm{~L}$ & $\mathrm{~L}$ & $\mathrm{~L}$ & $\mathrm{~L}$ & $\mathrm{~L}$ \\
\hline Gong et al (20) & 2016 & $\mathrm{~L}$ & $\mathrm{~L}$ & $\mathrm{~L}$ & $\mathrm{~L}$ & $\mathrm{~L}$ & $\mathrm{~L}$ & $\mathrm{~L}$ \\
\hline Ju (39) & 2007 & $\mathrm{~L}$ & $\mathrm{~L}$ & $\mathrm{~L}$ & $\mathrm{~L}$ & $\mathrm{~L}$ & $\mathrm{~L}$ & $\mathrm{~L}$ \\
\hline Ge et al (8) & 2005 & $\mathrm{~L}$ & $\mathrm{U}$ & $\mathrm{L}$ & $\mathrm{L}$ & $\mathrm{L}$ & $\mathrm{L}$ & $\mathrm{L}$ \\
\hline Luo (27) & 2012 & $\mathrm{~L}$ & $\mathrm{U}$ & $\mathrm{L}$ & $\mathrm{L}$ & $\mathrm{L}$ & $\mathrm{L}$ & $\mathrm{L}$ \\
\hline Li et al (30) & 2016 & $\mathrm{~L}$ & $\mathrm{~L}$ & $\mathrm{~L}$ & $\mathrm{~L}$ & $\mathrm{~L}$ & $\mathrm{~L}$ & $\mathrm{~L}$ \\
\hline Wang et al (10) & 2012 & $\mathrm{~L}$ & $\mathrm{~L}$ & $\mathrm{~L}$ & $\mathrm{~L}$ & $\mathrm{~L}$ & $\mathrm{~L}$ & $\mathrm{~L}$ \\
\hline Ye (31) & 2006 & $\mathrm{~L}$ & $\mathrm{~L}$ & $\mathrm{~L}$ & $\mathrm{~L}$ & $\mathrm{~L}$ & $\mathrm{~L}$ & $\mathrm{~L}$ \\
\hline Person et al (21) & 2015 & $\mathrm{~L}$ & $\mathrm{~L}$ & $\mathrm{~L}$ & $\mathrm{~L}$ & $\mathrm{~L}$ & $\mathrm{~L}$ & $\mathrm{~L}$ \\
\hline Lau et al (5) & 2004 & $\mathrm{~L}$ & $\mathrm{~L}$ & $\mathrm{~L}$ & $\mathrm{~L}$ & $\mathrm{~L}$ & $\mathrm{~L}$ & $\mathrm{~L}$ \\
\hline
\end{tabular}

1, Random sequence generation (selection bias); 2, Allocation concealment (selection bias); 3, Blinding of participants and personnel (performance bias); 4, Blinding of outcome assessment (detection bias); 5, Incomplete outcome data (attrition bias); 6 , selective reporting (reporting bias); 7, Other bias; L, low risk of bias; $\mathrm{U}$, unclear risk of bias; $\mathrm{H}$, high risk of bias. 


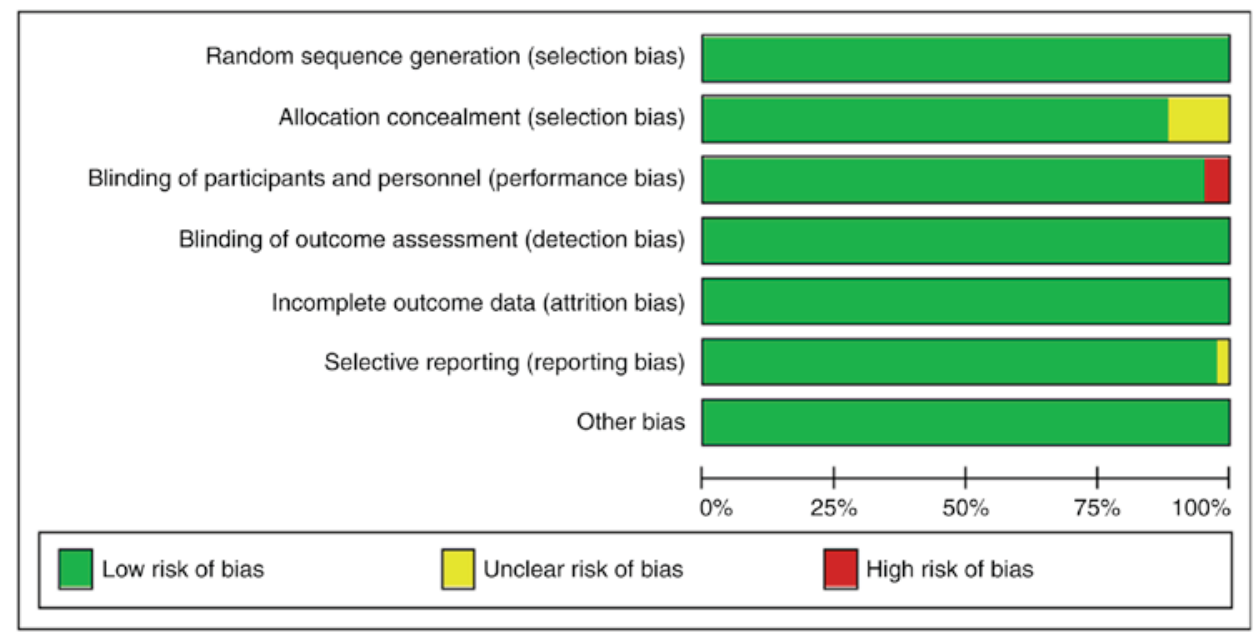

Figure 2. Risk of bias graph.

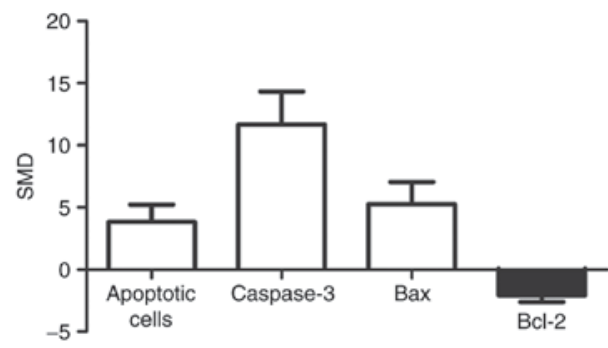

Figure 3. Effects of arsenic on apoptosis. SMD, standardized mean difference; caspase-3, cysteinyl aspartate-specific protease-3; Bcl-2, B-cell lymphoma/leukemia-2 protein; Bax, Bcl-associated X protein.

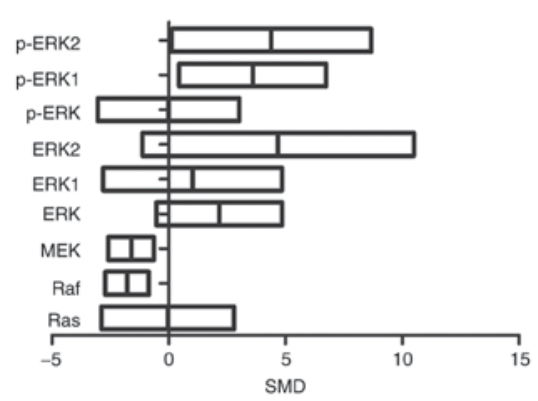

Figure 4. Effects of arsenic exposure on ERK. SMD, standardized mean difference; ERK, extracellular signal-regulated MAP kinases; MEK, mitogen-induced extracellular kinase; p-ERK, phosphorylated extracellular signal-regulated kinase; Raf, serine/threonine-specific protein kinases.

( $\geq 2 \mu \mathrm{mol} / 1)$. Conversely decreased expressions of Ras $(\mathrm{SMD}=-3.96,95 \%$ CI $(-5.36,-2.56))$, ERK1 (SMD=-10.11, 95\% CI (-18.40, -1.81) ), p-ERK (SMD=-6.07, 95\% CI (-11.89, -0.26)), p-ERK2 (SMD=-20.34, 95\% CI (-39.58, -1.11)) were seen with low doses $(<2 \mu \mathrm{mol} / \mathrm{l})$ (Fig. 8).

Small-study effect evaluation. The funnel plot (Fig. 9) shows that there was a symmetrical distribution of all the studies, suggesting no significant small-study effects.

Sensitivity analysis. A sensitivity analysis was performed for p-ERK. The results of all the studies were distributed evenly
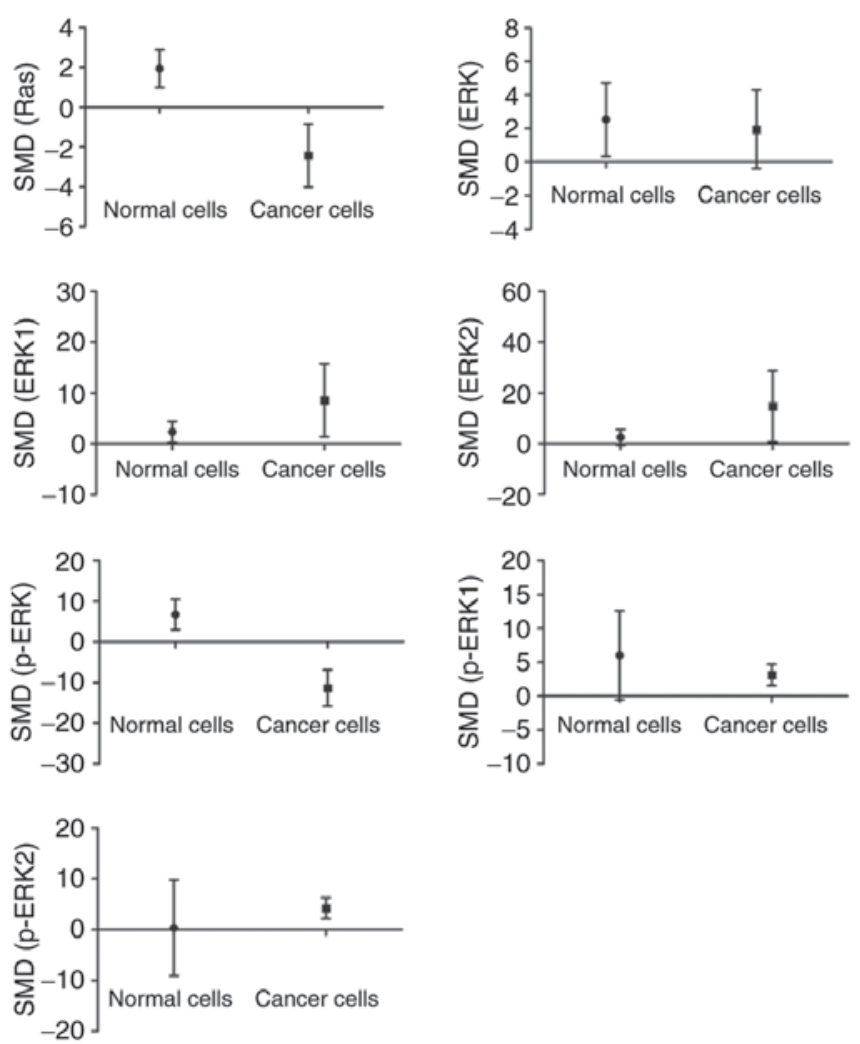

Figure 5. Subgroup analyses to determine the effects of arsenic on ERK based on source. SMD, standardized mean difference; ERK, extracellular signal-regulated MAP kinases; MEK, mitogen-induced extracellular kinase; p-ERK, phosphorylated extracellular signal-regulated kinase.

from the center line and no significant deviation was seen. Thus, there seems to be no individual study affecting the combined results (Fig. 10).

\section{Discussion}

Arsenic contributes to cell apoptosis (3) leading to serious damage (23). However, arsenic has recently been explored for its anti-tumor ability in leukemia and other malignant tumors 


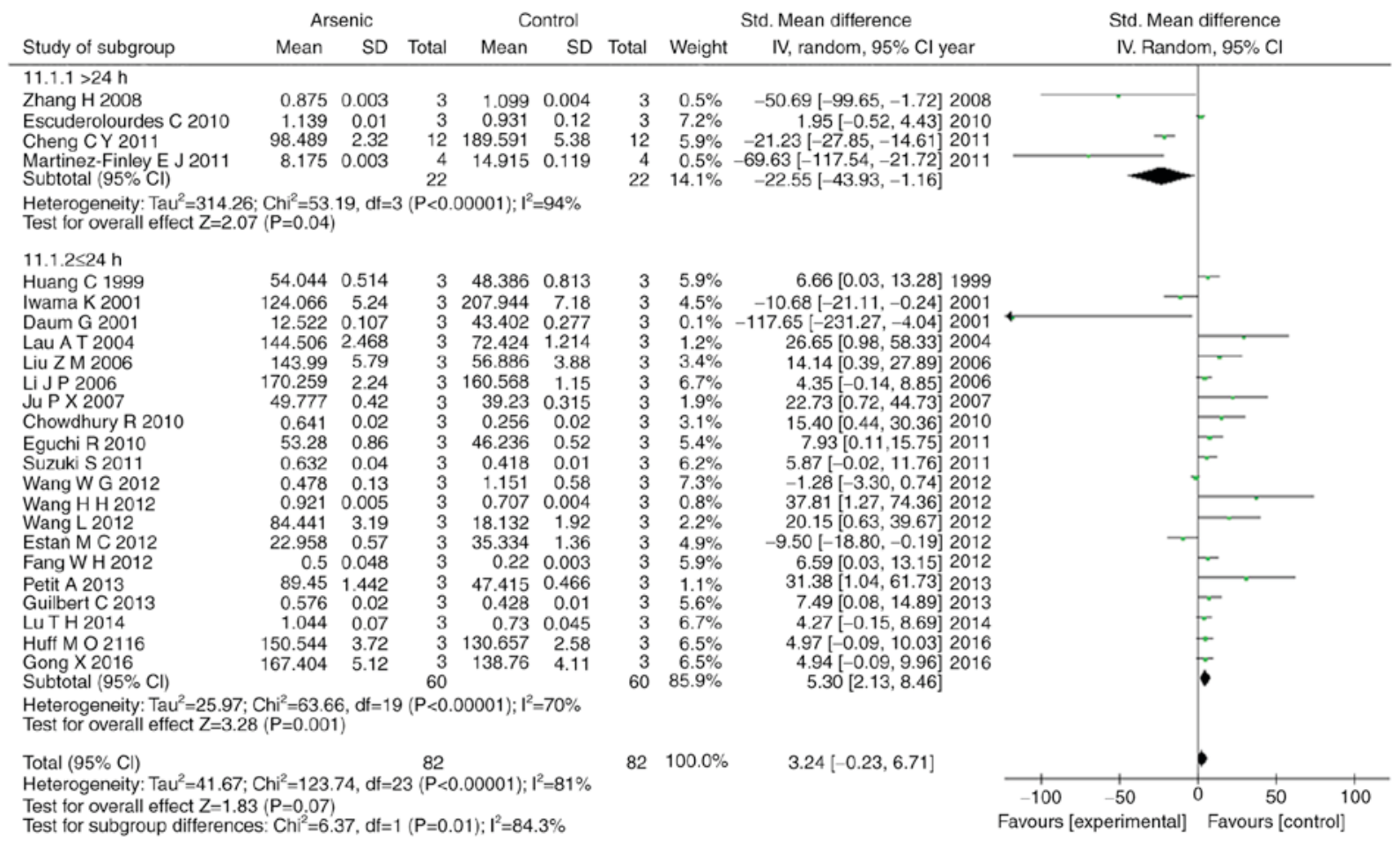

Figure 6. Subgroup analyses to determine the effects of arsenic on p-ERK1 based on exposure time. Forest plot showing the impact of arsenic treatment on p-ERK1 compared to controls. Total column represents total number of studies performed. SMD, standardized mean difference; IV, independent variable; $95 \%$ CI, $95 \%$ confidence interval; SD, standard deviation.

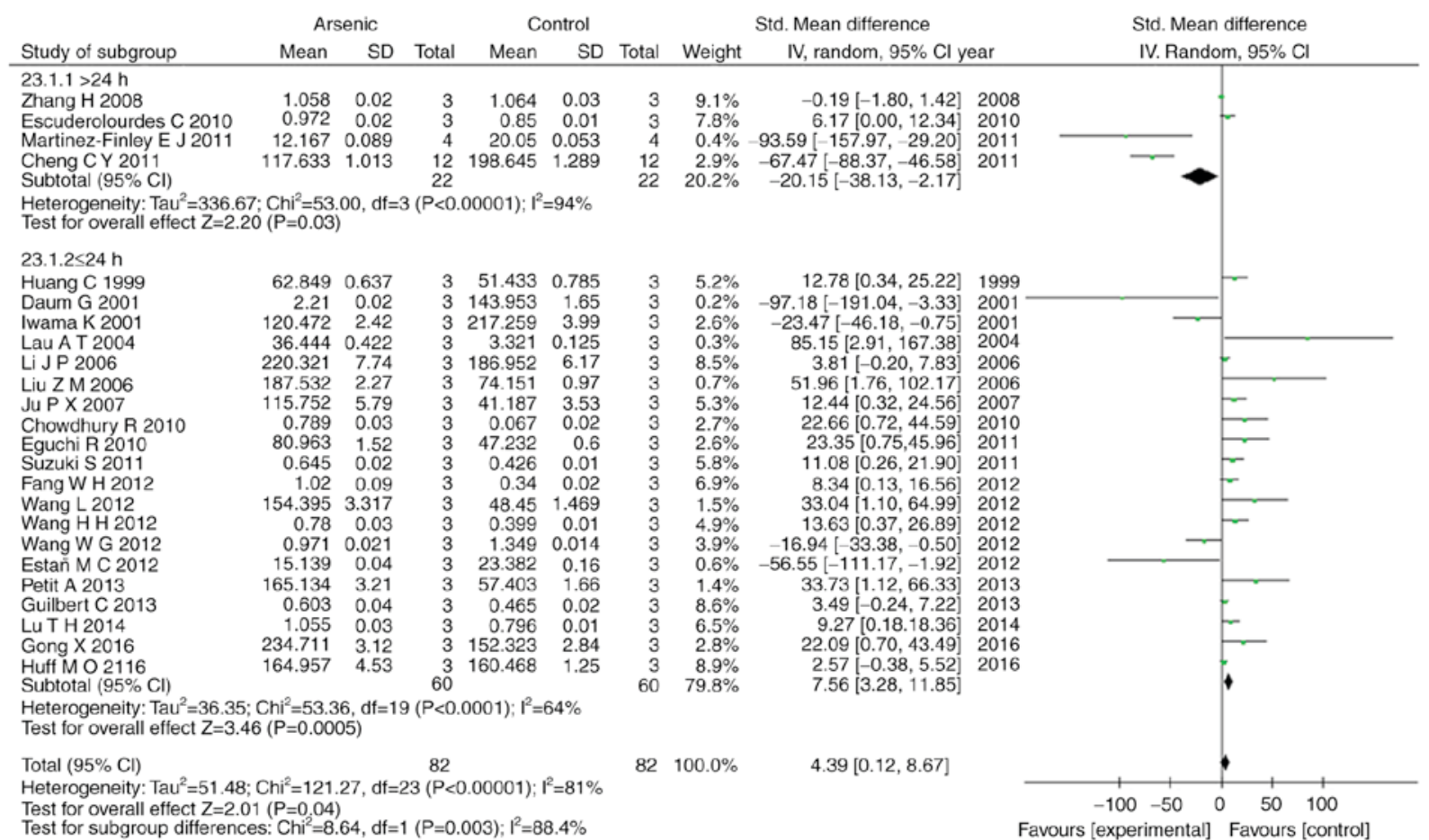

Figure 7. Subgroup analyses to determine the effects of arsenic on p-ERK2 based on exposure time. Forest plot showing the impact of arsenic treatment on p-ERK2 compared to controls. Total column represents total number of studies performed. SMD, standardized mean difference; IV, independent variable; $95 \%$ CI, $95 \%$ confidence interval; SD, standard deviation.

using its induction of apoptosis (24). ERK had been reported to participate in arsenic-induced apoptosis (25), but reports on the interaction between arsenic and ERK signaling pathway were inconsistent. In our meta-analysis, we found that arsenic had a bidirectional effect on ERK signaling pathway. Arsenic could activate it in the normal cell, but inhibit ERK pathway in cancer cell line, which was also related to dosage and exposure time. These findings provided a divergent theoretical basis 

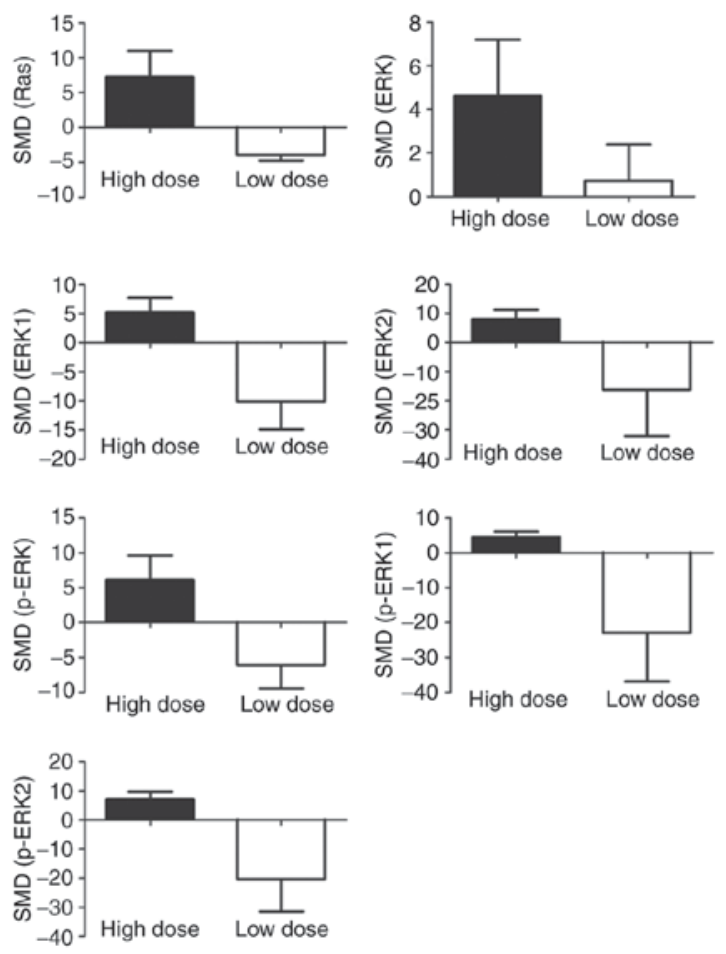

Figure 8. Subgroup analysis based on dosage of arsenic. SMD, standardized mean difference. ERK, extracellular signal-regulated MAP kinases; MEK, mitogen-induced extracellular kinase; p-ERK, phosphorylated extracellular signal-regulated kinase.

of injurious as well as beneficial therapeutic mechanisms of arsenic.

Apoptosis is of great significance in maintaining normal development and homeostasis (26). As shown in Fig. 3, apoptotic cells, pro-apoptotic protein (Bax) and activity of caspase-3 had increased while anti-apoptotic protein (Bcl-2) had decreased suggesting an undoubted proof of arsenic-induced apoptosis.

Present results suggested that ERK plays an opposing role in normal and cancer cells. Luo (27) and Banerjee et al (28) had reported that in normal cells, arsenic-induced apoptosis was brought about by activation of ERK signaling pathway. As shown in Fig. 5, it can be seen that arsenic increased levels of Ras and p-ERK in normal cells indicating that arsenic led to ERK signaling pathway activation. As for cancer cells, induction of apoptosis is one of the most efficient approaches for the clinical treatment of cancer. It had been reported that arsenic-induced apoptosis of cancer cells was correlated with inhibition of ERK (29-32). Furthermore, arsenic inhibition of ERK signaling pathway in human leukemia cells was also verified as a fact $(7,10,24,33)$. Likewise, decreased levels of both Ras and p-ERK were shown in cancer cells (Fig. 5) along with restraint of ERK signaling. Obviously, the mechanism of arsenic-induced apoptosis is different between normal cells and cancer cells.

ERK was also considered an important mechanism of arsenic causing toxic injury $(34,35)$. Our results showed that arsenic increased the levels of Ras and p-ERK in normal cells (Fig. 5), suggesting that arsenic may activate ERK signaling pathway via Ras/Raf/MEK/ERK pathways. Some studies stated that the activation of ERK signaling pathway leads to DNA damage steering genetic toxicity $(36,37)$. These results

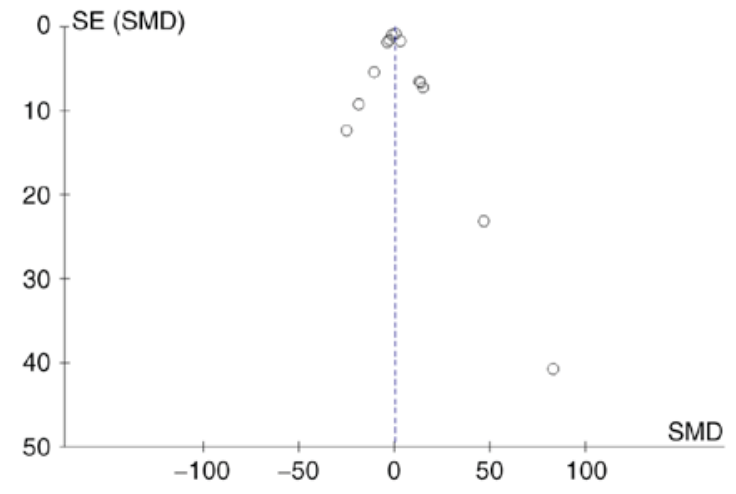

Figure 9. Funnel Plot for p-ERK. Blue-dotted line shows overall estimated standard mean difference. Evidence for publication bias was not found $(\mathrm{P}=0.490)$. SMD, standard mean difference; SE, standard error; p-ERK, phosphorylated extracellular signal-regulated kinase.

also demonstrated that arsenic, through activation of ERK signaling pathway in normal cells, causes toxicity. Activated ERK had been reported to be involved in pathogenesis and development of tumor and cancer $(30,38)$. In this study, cancer cells exposed to arsenic had decreased levels of Ras and p-ERK (Fig. 5) and thus induced suppression of ERK signaling pathway. Therefore, arsenic could inhibit the development of tumor by restraining ERK signaling.

A difference in arsenic doses and exposure time could account for opposite effects caused by arsenic on ERK activity. Ju (39) found out that high doses and short exposure time of arsenic led to activation of ERK. This point was also testified by other studies $(40,41)$. However, some studies $(42,43)$ showed that low doses and long exposure time of arsenic contributed to inactivation of ERK signaling pathway. These discoveries were consistent with the results of this meta-analysis, suggesting that high dose and short exposure time may lead to ERK signaling pathway activation, while low dose and long exposure time depress the activation of ERK signaling.

From what has been discussed above, we may reasonably conclude that ERK signaling pathway was activated when normal cells were exposed to high doses of arsenic for a short period of time, contributing to cell apoptosis, explaining the toxic injury caused by arsenic (Fig. 11A). As for cancer cells, low dose arsenic intervention for long period of time may play a role in promoting cell apoptosis by inhibiting ERK signaling pathway thus suppressing the growth of the tumor (Fig. 11B). These findings not only contributed to a potential approach for seeking ERK inhibitors which work against toxic injury but also provided a reference for a long-term treatment of cancer with low doses of arsenic.

The literature incorporated in this study exhibit heterogeneity. It may also be related to certain factors such as strains of objects, the method of arsenic exposure and possibly others in addition to the factors shown in subgroup analysis. The existing literature did not provide a detailed description of the said factors. Moreover, the data in the selected papers do not support our comparison of time and dose together. Arsenic also affects JNK, p38 and other MAPK signaling pathways and whether ERK interacts with all these may be regarded as a new direction for future research. 


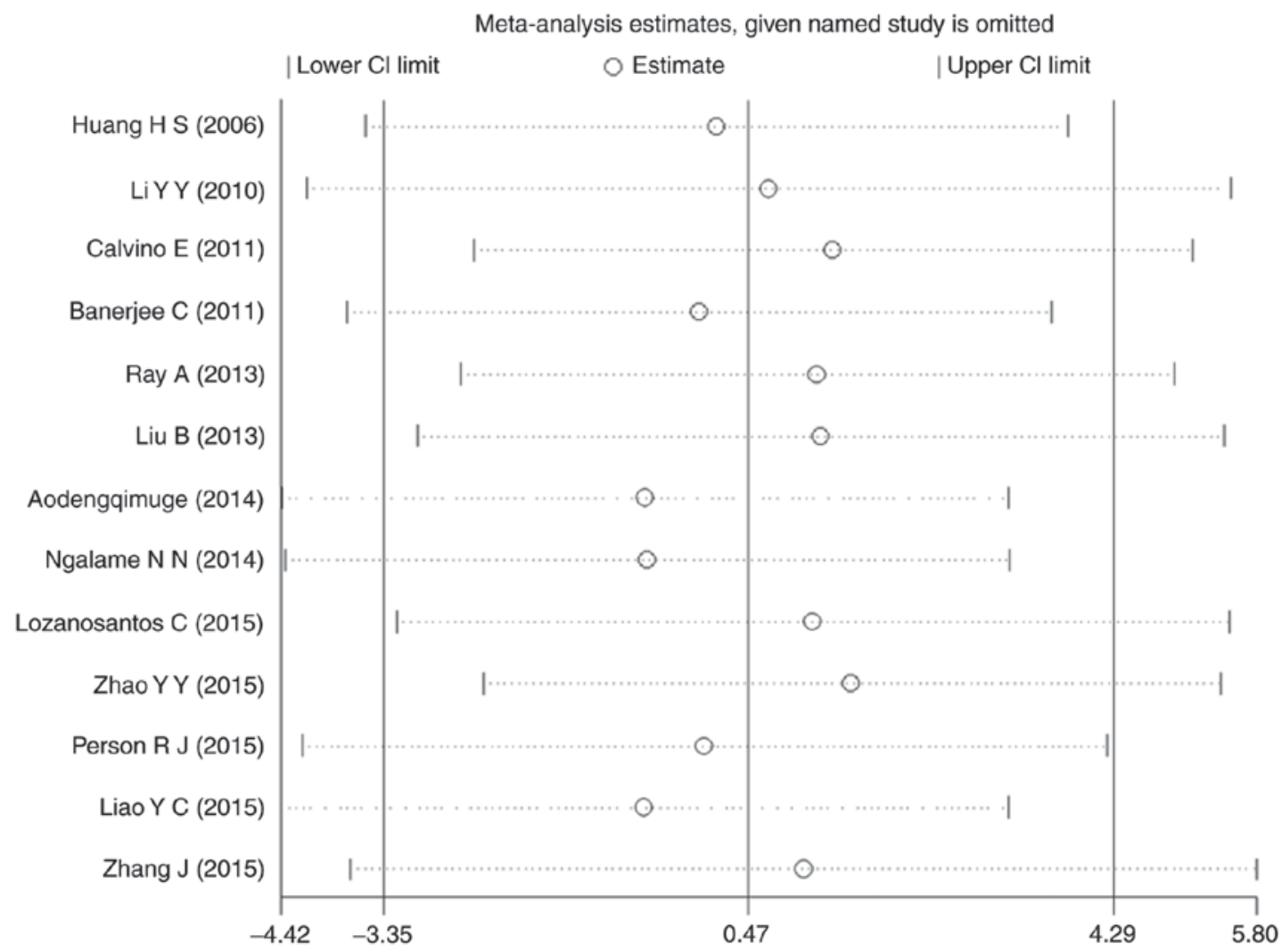

Figure 10. Sensitivity analysis for p-ERK. Stable results were observed for all the studies, indicating no individual study influencing the combined results. CI, confidence interval; p-ERK, phosphorylated extracellular signal-regulated kinase.
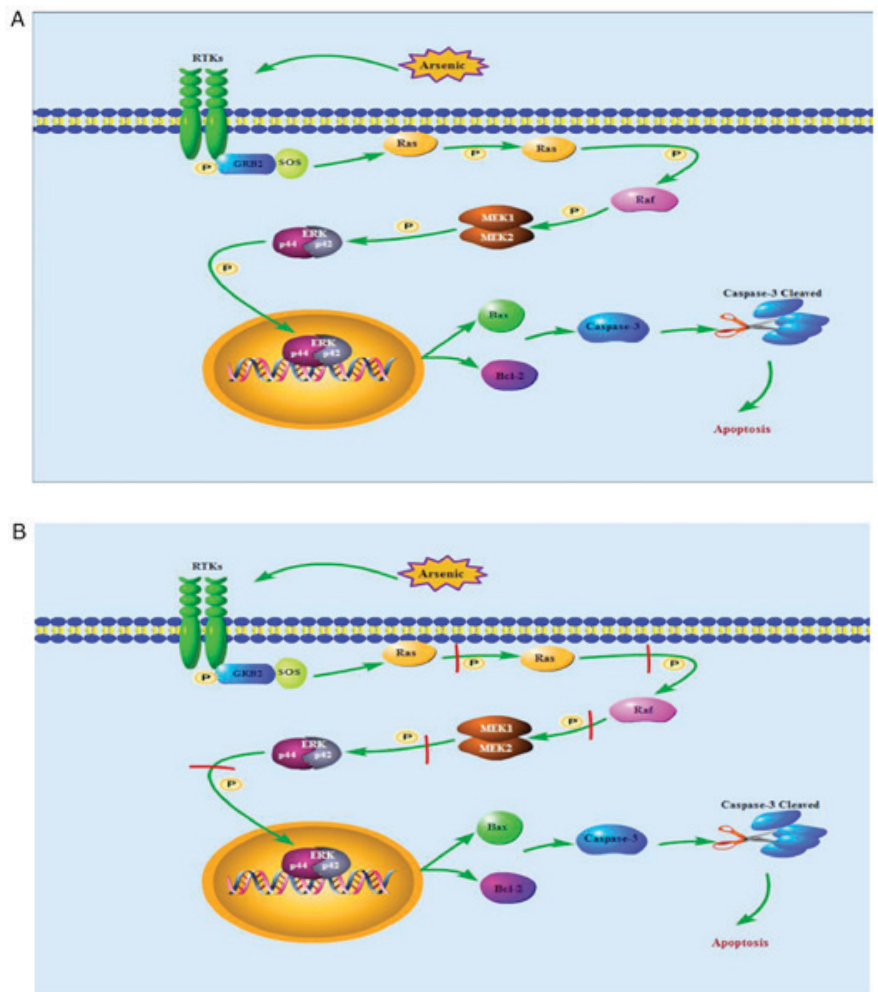

Figure 11. The ERK signaling pathway. (A) shows that high doses of arsenic for a short period of time enhances Ras, Raf, MEK and ERK phosphorylation in normal cells, thereby the activated ERK translocates from cytoplasm into nucleus, increases levels of Bax protein, decreases levels of Bcl-2 protein and cleaves caspase-3, contributing to cell apoptosis. (B) indicates that, in cancer cells, low dose arsenic intervention for long period of time suppresses phosphorylation of Ras, Raf, MEK and ERK, blocking ERK translocation from cytoplasm into nucleus, thereby increases levels of Bax protein, decreases levels of Bcl-2 protein and cleaves caspase-3, contributing to cell apoptosis. ERK, extracellular signal-regulated MAP kinases; MEK, mitogen-induced extracellular kinase; p-ERK, phosphorylated extracellular signal-regulated kinase; Raf, serine/threonine-specific protein kinases; Bcl-2, B-cell lymphoma/leukemia-2 protein; Bax, Bcl-associated X protein; caspase-3, cysteinyl aspartate-specific protease-3; RTKs, receptor tyrosine kinases. 


\section{Acknowledgements}

The authors would like to thank the Department of Public Health, Shihezi University School of Medicine for assistance with this work, as well as funding from the National Natural Science Foundation of China (no. 81560517 and 81760584), the Key Areas of Science and Technology Research Project of Xinjiang Production and Construction Corps (nos. 2014BA039 and 2015AG014) and the International Cooperative Project of Shihezi University (no. GJHZ201602).

\section{References}

1. Singh N, Kumar D, Lal K, Raisuddin S and Sahu AP: Adverse health effects due to arsenic exposure: Modification by dietary supplementation of jaggery in mice. Toxicol Appl Pharmacol 242: 247-255, 2010 .

2. Yen CC, Ho TJ, Wu CC, Chang CF, Su CC, Chen YW, Jinn TR, $\mathrm{Lu} \mathrm{TH}$, Cheng PW, Su YC and Liu SH: Inorganic arsenic causes cell apoptosis in mouse cerebrum through an oxidative stress-regulated signaling pathway. Arch Toxicol 85: 565-575, 2011.

3. Eguchi R, Fujimori Y, Takeda H, Tabata C, Ohta T, Kuribayashi K, Fukuoka $\mathrm{K}$ and Nakano T: Arsenic trioxide induces apoptosis through JNK and ERK in human mesothelioma cells. J Cell Physiol 226: 762-768, 2011.

4. Ray A, Chatterjee S, Mukherjee S and Bhattacharya S: Interplay of loss of ERK dependence and amplification of apoptotic signals in arsenic treated rat hepatocytes. Natl Acad Sci Lett 36: 599-602, 2013

5. Lau AT, Li M, Xie R, He QY and Chiu JF: Opposed arsenite-induced signaling pathways promote cell proliferation or apoptosis in cultured lung cells. Carcinogenesis 25: 21-28, 2004.

6. Li JP, Lin JC and Yang JL: ERK activation in arsenite-treated G1-enriched CL3 cells contributes to survival, DNA repair inhibition, and micronucleus formation. Toxicol Sci 89: 164-172, 2006.

7. Lozano-Santos C, Amigo-Jiménez I, Nova-Gurumeta S, Pérez-Sanz N, García-Pardo A and García-Marco JA: Arsenic trioxide synergistically potentiates the cytotoxic effect of fludarabine in chronic lymphocytic leukemia cells by further inactivating the AKT and ERK signaling pathways. Biochem Biophys Res Commun 461: 243-248, 2015.

8. Ge Y, Xu G and Zhang C: The effects of arsenious acid on the apoptosis and the expression of ERK-1 protein of human hepatocarcinoma cells. J Anhui Med Univ 40: 412-414, 2005.

9. Escudero-Lourdes C, Medeiros MK, Cárdenas-González MC Wnek SM and Gandolfi JA: Low level exposure to monomethyl arsenous acid-induced the over-production of inflammation-related cytokines and the activation of cell signals associated with tumor progression in a urothelial cell model. Toxicol Appl Pharmacol 244: 162-173, 2010.

10. Wang WG, Ma LL and Sun BL: Arsenic trioxide induces apoptosis and inhibit activity of ERK in HL-60 cells. J Mod Oncol 20 : 39-42, 2012.

11. Daum G, Pham J and D eou J: Arsenite inhibits Ras-dependent activation of ERK but activates ERK in the presence of oncogenic Ras in baboon vascular smooth muscle cells. Mol Cell Biochem 217: 131-136, 2001.

12. Benbrahim-Tallaa L, Waterland RA, Styblo M, Achanzar WE, Webber MM and Waalkes MP: Molecular events associated with arsenic-induced malignant transformation of human prostatic epithelial cells: Aberrant genomic DNA methylation and K-ras oncogene activation. Toxicol Appl Pharmacol 206: 288-298, 2005 .

13. Chowdhury R, Chatterjee R, Giri AK, Mandal C and Chaudhuri K: Arsenic-induced cell proliferation is associated with enhanced ROS generation, ERK signaling and CyclinA expression. Toxicol Lett 198: 263-271, 2010.

14. Li YY, Jiang YF, Yang YY, Wang R, Zhang BY, Li L and Mu XL: Effects of JNK ERK signaling pathway in proliferation of bone marrow mesenchymal stem cells induced by $\mathrm{NaAsO}_{2}$. Prog Mod Biomed 8: 1464-1466, 2010.

15. Suzuki S, Inaba H, Satoh T, Okazaki $\mathrm{T}$ and Takahashi $\mathrm{S}$ : Activation of ERK and p38 by the addition of arsenic trioxide in Flt3-ITD cells. Open J Blood Dis 1: 9-11, 2011.
16. Guilbert C, Annis MG, Dong Z, Siegel PM, Miller WH Jr and Mann KK: Arsenic trioxide overcomes rapamycin-induced feedback activation of AKT and ERK signaling to enhance the anti-tumor effects in breast cancer. PLoS One 8: e85995, 2013.

17. Huff MO, Todd SL, Smith AL, Elpers JT, Smith AP, Murphy RD, Bleser-Shartzer AS, Hoerter JE, Radde BN and Klinge CM: Arsenite and cadmium activate MAPK/ERK via membrane estrogen receptors and G-protein coupled estrogen receptor signaling in human lung adenocarcinoma cells. Toxicol Sci 152: 62-71, 2016.

18. Wang L, Kou MC, Weng CY, Hu LW, Wang YJ and Wu MJ: Arsenic modulates heme oxygenase- 1 , interleukin- 6 , and vascular endothelial growth factor expression in endothelial cells: Roles of ROS NF-kB, and MAPK pathways. Arch Toxicol 86: 879-896, 2012.

19. Aodengqimuge, Liu S, Mai S, Li X, Li Y, Hu M, Yuan S and Song L: AP-1 activation attenuates the arsenite-induced apoptotic response in human bronchial epithelial cells by up-regulating HO-1 expression. Biotechnol Lett 36: 1927-1936, 2014.

20. Gong X, Ivanov VN and Hei TK: 2,3,5,6-Tetramethylpyrazine (TMP) down-regulated arsenic-induced heme oxygenase- 1 and ARS2 expression by inhibiting Nrf2, NF- $\kappa \mathrm{B}, \mathrm{AP}-1$ and MAPK pathways in human proximal tubular cells. Arch Toxicol 90: 2187-2200, 2016.

21. Person RJ, Ngalame NN, Makia NL, Bell MW, Waalkes MP and Tokar EJ: Chronic inorganic arsenic exposure in vitro induces a cancer cell phenotype in human peripheral lung epithelial cells. Toxicol Appl Pharmacol 286: 36-43, 2015.

22. Huang C, Ma WY, Li J, Goranson A and Dong Z: Requirement of ERK, but not JNK, for arsenite-induced cell transformation. J Biol Chem 274: 14595-14601, 1999.

23. Martinez-Finley EJ, Goggin SL, Labrecque MT and Allan AM: Reduced expression of MAPK/ERK genes in perinatal arsenic-exposed offspring induced by glucocorticoid receptor deficits. Neurotoxicol Teratol 33: 530-537, 2011.

24. Estañ MC, Calviño E, de Blas E, Boyano-Adánez Mdel C, Mena ML, Gómez-Gómez M, Rial E and Aller P: 2-Deoxy-D-glucose cooperates with arsenic trioxide to induce apoptosis in leukemia cells: Involvement of IGF-1R-regulated Akt/mTOR, MEK/ERK and LKB-1/AMPK signaling pathways. Biochem Pharmacol 84: 1604-1616, 2012.

25. Zheng TH, Guo QJ, Wang FM and Liu XH: Extracellular signal-regulated kinase $1 / 2$ (ERK1/2) participates in the glioma apoptosis induced by $\mathrm{As}_{2} \mathrm{O}_{3}$. J Mod Oncol 14: 1341-1344, 2006.

26. Zhang J: Effects of Fluoride, Arsenic and co-exposure on learning and memory and Ras/ERK pathway in rats (dissertation). Med Univ Xinjiang, 2015.

27. Luo P, Zhang AH, Zhang KJ, Zeng XP, Fang WH, Ye JF, Xiao JY, Zhang $\mathrm{Y}$ and Wu XY: The change of ERKs expression in L-02 cell damage process cause by $\mathrm{NaAsO}_{2}$. Chin Soc Toxicol 27: 387-388, 2013 (In Chinese).

28. Banerjee C, Goswami R, Datta S, Rajagopal R and Mazumder S: Arsenic-induced alteration in intracellular calcium homeostasis induces head kidney macrophage apoptosis involving the activation of calpain-2 and ERK in Clarias batrachus. Toxicol Appl Pharmacol 256: 44-51, 2011.

29. Wu J, Luo RC, Zhang H and Cui YZ: Inhibitory effect of sorafenib combined with arsenic trioxide on hepatocellular carcinoma cells. Nan Fang Yi Ke Da Xue Xue Bao 28: 639-641, 2008 (In Chinese).

30. Li P, Gong XJ and Cao W: Effect of ERK activation and As2O3 in the apoptosis of anaplastic thyroid cancer cell line FRO. Oncol Prog 14: 879-881, 2016.

31. Ye J: Involvement of JWA and MAPK in apoptosis induced by Arsenic trioxide in MCF-7 and Hela cells and cell differentiation induced by TPA in MCF-7 cells (unpublished PhD thesis). Med Univ Nanjing, 2006.

32. Iwama K, Nakajo S, Aiuchi T and Nakaya K: Apoptosis induced by arsenic trioxide in leukemia U937 cells is dependent on activation of $\mathrm{p} 38$, inactivation of ERK and the $\mathrm{Ca} 2+$-dependent production of superoxide. Int J Cancer 92: 518-526, 2001.

33. Calviño E, Estañ MC, Simón GP, Sancho P, Boyano-Adánez Mdel C, de Blas E, Bréard J and Aller P: Increased apoptotic efficacy of lonidamine plus arsenic trioxide combination in human leukemia cells. Reactive oxygen species generation and defensive protein kinase (MEK/ERK, Akt/mTOR) modulation. Biochem Pharmacol 82: 1619-1629, 2011.

34. Liu ZM and Huang HS: $\mathrm{As}_{2} \mathrm{O}_{3}$-induced c-Src/EGFR/ERK signaling is via $\mathrm{Spl}$ binding sites to stimulate p21WAF1/CIP1 expression in human epidermoid carcinoma A431 cells. Cell Signal 18: 244-255, 2006. 
35. Huang HS, Liu ZM, Ding L, Chang WC, Hsu PY, Wang SH, Chi CC and Chuang CH: Opposite effect of ERK1/2 and JNK on $\mathrm{p} 53$-independent $\mathrm{p} 21 \mathrm{WAF} 1 / \mathrm{CIP} 1$ activation involved in the arsenic trioxide-induced human epidermoid carcinoma A431 cellular cytotoxicity. J Biomed Sci 13: 113-125, 2006.

36. Liao YC, Chen YF and Lee TC: Increased susceptibility of H-Ras(G12V)-transformed human urothelial cells to the genotoxic effects of sodium arsenite. Arch Toxicol 89: 1971-1979, 2015.

37. Wang HH: The effect and mechanism study of sodium arsenic induces cyclooxygenase-2 expression in Human urothelial cells (unpublished PhD thesis). Med Univ China, 2012.

38. Ngalame NN, Tokar EJ, Person RJ, Xu Y and Waalkes MP. Aberrant microRNA expression likely controls RAS oncogene activation during malignant transformation of human prostate epithelial and stem cells by arsenic. Toxicol Sci 138: 268-277, 2014.

39. Ju PX: Signal transduction mechanism for $\mathrm{As}_{2} \mathrm{O}_{3}$-induced non-small cell lung cancer cell apoptosis (unpublished $\mathrm{PhD}$ thesis). Med Univ China, 2007.

40. Petit A, Delaune A, Falluel-Morel A, Goullé JP, Vannier JP, Dubus I and Vasse M: Importance of ERK activation in As2O3-induced differentiation and promyelocytic leukemia nuclear bodies formation in neuroblastoma cells. Pharmacol Res 77: 11-21, 2013
41. Lu TH, Tseng TJ, Su CC, Tang FC, Yen CC, Liu YY, Yang CY, Wu CC, Chen KL, Hung DZ and Chen YW: Arsenic induces reactive oxygen species-caused neuronal cell apoptosis through JNK/ERK-mediated mitochondria-dependent and GRP 78/CHOP-regulated pathways. Toxicol Lett 224: 130-140, 2014.

42. Liu B, Zhao Y, Yu L, He X and Zhang B: Study on the role of Ras/p-ERK signaling pathway in the reversing effect of $\mathrm{As}_{2} \mathrm{O}_{3}$ on multi-drug-resistance. Chin J Clin Oncol 40: 505-512, 2013 .

43. Zhao YY, Yu L, Liu BL, He XJ and Zhang BY: Downregulation of P-gp, Ras and p-ERK1/2 contributes to the arsenic trioxide-induced reduction in drug resistance towards doxorubicin in gastric cancer cell lines. Mol Med Rep 12: 7335-7343, 2015.

This work is licensed under a Creative Commons Attribution-NonCommercial-NoDerivatives 4.0 International (CC BY-NC-ND 4.0) License. 